\title{
Ground Motion Modeling in the Eastern Caucasus
}

\author{
Arben Pitarka, ${ }^{1}$ Rengin GoK, ${ }^{1}$ Gurban YetiRmishli, ${ }^{2}$ Saida Ismayilova, ${ }^{2}$ and Robert Mellors ${ }^{1}$
}

\begin{abstract}
In this study, we analyzed the performance of a preliminary three-dimensional (3D) velocity model of the Eastern Caucasus covering most of the Azerbaijan. The model was developed in support to long-period ground motion simulations and seismic hazard assessment from regional earthquakes in Azerbaijan. The model's performance was investigated by simulating ground motion from the damaging Mw 5.9, 2012 Zaqatala earthquake, which was well recorded throughout the region by broadband seismic instruments. In our simulations, we use a parallelized finite-difference method of fourth-order accuracy. The comparison between the simulated and recorded ground motion velocity in the modeled period range of 3-20 s shows that in general, the 3D velocity model performs well. Areas in which the model needs improvements are located mainly in the central part of the Kura basin and in the Caspian Sea coastal areas. Comparisons of simulated ground motion using our $3 \mathrm{D}$ velocity model and corresponding $1 \mathrm{D}$ regional velocity model were used to locate areas with strong 3D wave propagation effects. In areas with complex underground structure, the $1 \mathrm{D}$ model fails to produce the observed ground motion amplitude and duration, and spatial extend of ground motion amplification caused by wave propagation effects.
\end{abstract}

Key words: Wave propagation modeling, strong ground motion, finite-difference technique, 3D velocity model, Azerbaijan, Kura basin.

\section{Introduction}

The Eastern Caucasus region has a long history of damaging earthquakes (KondorsKaya and SHEBALIN 1977; Storchá et al. 2013). The high seismicity, rapid population growth, and a recent increase in civil, industrial, and infrastructure construction suggest for

This work was performed under the auspices of the U.S. Department of Energy by Lawrence Livermore National Laboratory under Contract DE-AC52-07NA27344, LLNL-JRNL-679075.

1 Lawrence Livermore National Laboratory, Livermore, USA. E-mail: pitarka1@1lnl.gov

2 Republic Seismic Survey Center, Azerbaijan National Academy of Sciences, Baku, Azerbaijan. significantly increased seismic risk in the region. A necessary step in assessing seismic risk is to estimate the hazard, i.e., a quantitative estimate of the expected ground motion during a specified time window. A variety of methods for estimating seismic hazard exist, but all require a good knowledge of wave propagation and attenuation.

In this study, we test the performance of a preliminary regional 3D velocity model developed by Gок et al. (2011) by simulating ground motion in the period range of 3-20 s from the Mw 5.9, May 7, 2012 Zaqatala earthquake, recorded in the Eastern Caucasus (Fig. 1). The simulated ground motion was compared with observed ground motion at seismic stations in the Azerbaijan region. Maps of simulated ground motion were then used to investigate $3 \mathrm{D}$ basin effects in the Azerbaijan region, and identify areas, where the 3D velocity model needs further refinement.

Seismic hazard assessment in regions with limited strong motion data and complex structure requires accurate 3D seismic velocity models that can be used to estimate ground motion amplification due to wave propagation effects. Hybrid methods that combine low- and high-frequency approaches for simulating broadband ground motion have produced reliable synthetic data that are useful to seismic hazard assessment and building response analysis (e.g., PItarka et al. 2000; Graves and Pitarka 2010). Simulations of strong ground motion at regional distances $(>200 \mathrm{~km})$ often rely on 1D velocity models that are mostly calibrated for travel time and long-period surface wave amplitude (e.g., Pulido et al. 2015). 1D models tend to overestimate the amplitude and duration of long-period waves (DREGER et al. 2015; RoDGERs et al. 1999). The absence of 3D structural heterogeneity in 1D velocity models can cause overestimation of the so-called wave trapping effect, or ringing effect, which typically generates 


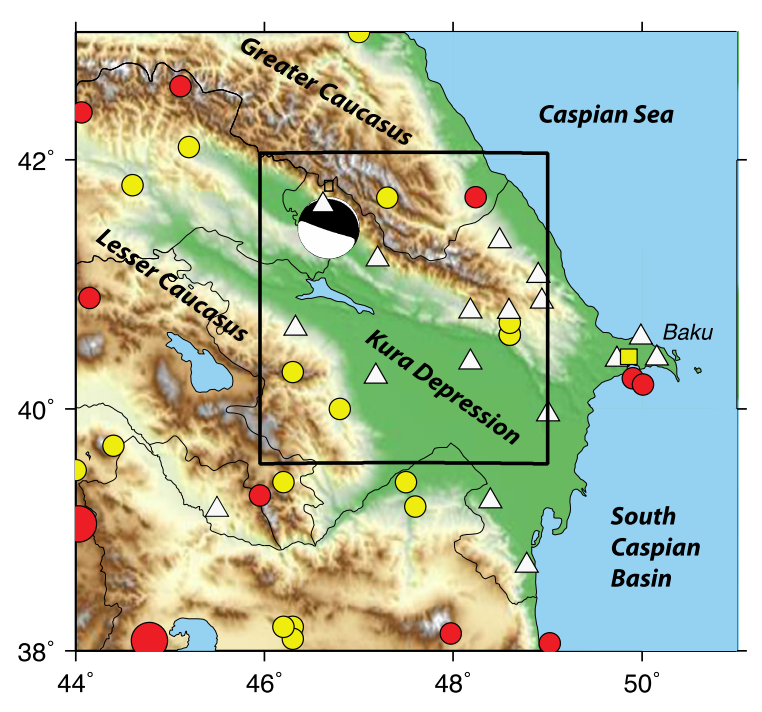

Figure 1

Topography map of the study region. The black square indicates the region covered by $3 \mathrm{D}$ velocity model. The seismic stations are indicated by white triangles. Red solid circles show the location of recent large (M6 and M7) earthquakes, recorded after 1906 (based on GEM catalog). The yellow solid circles show the location of damaging historical earthquakes (KondorsKAYA and SHEBALIN 1977). The focal mechanism is that of the May 7, 2012 Zaqatala earthquake. Yellow square on the east indicates the capital city of Baku

dispersive surface waves with extremely long duration. In contrast, 3D models allow for realistic modeling of wave scattering caused by wave conversions, reflections, and focusing and defocusing in heterogeneous underground structures. Earthquake ground motion modeling requires crustal models with high spatial resolution, especially in basins areas with sharp velocity contrast and large multi-scale structural variability.

\section{Tectonics, Underground Structure, and $3 D$ Velocity Model}

The Azerbaijan region lies in a complex and relatively poorly understood tectonic setting of Eastern Caucasus. The northern region is dominated by shortening along the Greater Caucasus, which is an area of complex active shortening at both crustal and deeper structures (e.g., ForTe et al. 2010). To the east is the Caspian Sea, which is underlain by two different basins: the South Caspian basin which has more than
$10 \mathrm{~km}$ of sediments and the North Caspian basin which has a thinner set of sediments on continental crust. Between the two basins is the Absheron structure, a zone of possible incipient subduction characterized by both crustal and intermediate depth seismicity (JACKSON et al. 2002). The southern part of the territory extends over the Lesser Caucasus and northern edge of the Iranian plateau. Between is the Kura Depression, with sediments up to $8 \mathrm{~km}$ thick that appears to be gradually subsumed under the Greater Caucasus. Below the sediments are meta-volcanic layers that resemble the surface geology of the Lesser Caucasus.

Various geophysical studies have examined the deep structure and velocity structure of the region. These include refraction and reflection profiles, deep boreholes, and passive seismic studies using earthquakes, receiver functions, and ambient noise. For this study, we used a smoothed and interpolated version of the crustal structure inferred by GoK et al. (2011), which was based on a joint inversion of receiver functions and surface waves, using both ambient noise and earthquake recordings measurements. The two sets of measurements were made using data from 14 broadband stations of the Azerbaijan network which provides a good stations coverage of the area. The Moho and basement depths in Gok et al. model were checked for consistency with other data where available, such as deep seismic sounding (DSS) measurements and borehole data at the $8 \mathrm{~km}$ deep Saatli well. Other studies of the underground structure based on active seismic sources or shallow borehole data cover very small areas.

Figure 2 shows maps of depth to basement, depth to shallow crustal layer, and Moho boundary extracted from model. In this figure, also shown are the surface topography and the stations location. The geometry of these boundaries as well as seismic velocities for each layer was used to generate a 3D regional velocity model. The seismic parameters assigned to each layer are shown in Table 1. We believe that this model captures the major crustal features, although discrepancies do exist. For example, in our model, the basement under Kura slopes down towards the Caspian, whereas there is evidence that an increase in basement elevation extends parallel to the Caspian coast (e.g., Kadirov 2000). 

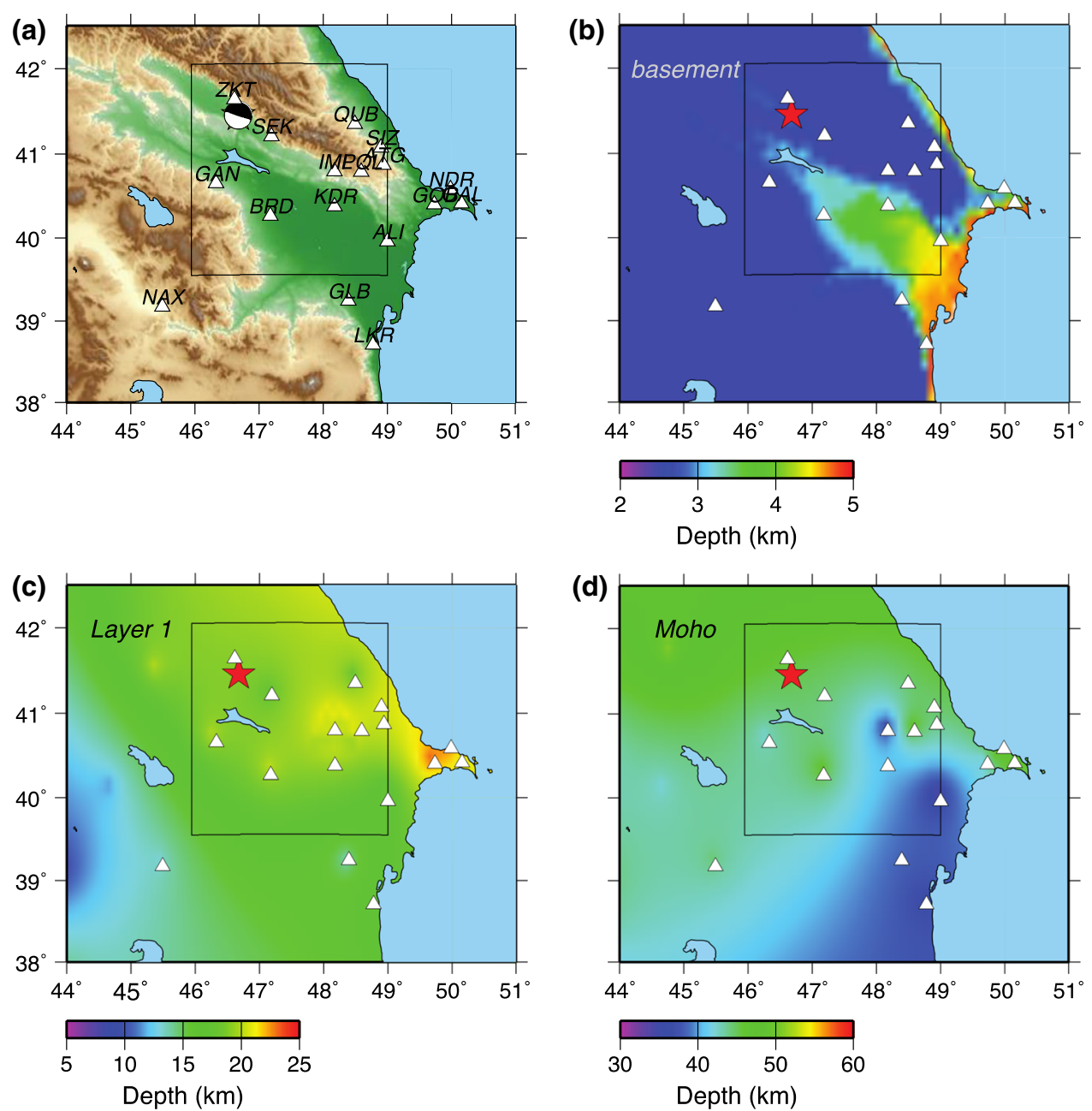

Figure 2

a Topography map of the Azerbaijan region. b Depth to the basement map. $\mathbf{c}$ Depth to the base of the first crustal layer. $\mathbf{d}$ Depth to the Moho boundary. Star indicates the earthquake epicenter, and triangles indicate the stations location. The black rectangle shows the area used in our wave propagation modeling

Table 1

Seismic velocity parameters used in the $3 D$ velocity model

\begin{tabular}{llclrl}
\hline Layer & $V_{\mathrm{P}}(\mathrm{m} / \mathrm{s})$ & $V_{\mathrm{S}}(\mathrm{m} / \mathrm{s})$ & Density $\left(\mathrm{g} / \mathrm{cm}^{3}\right)$ & $Q_{\mathrm{P}}$ & $Q_{\mathrm{S}}$ \\
\hline Basin & 1700 & 800 & 2.1 & 300 & 150 \\
Layer 1 & 4000 & 2310 & 2.2 & 400 & 200 \\
Layer 2 & 5000 & 2886 & 2.5 & 500 & 250 \\
Crust & 6500 & 3800 & 3.0 & 800 & 400 \\
Mantle & 7500 & 4350 & 3.2 & 1000 & 500 \\
\hline
\end{tabular}

However, full consideration of all available geologic and geophysical data is beyond the scope of this study which is mainly focused on long-period ground motion modeling.

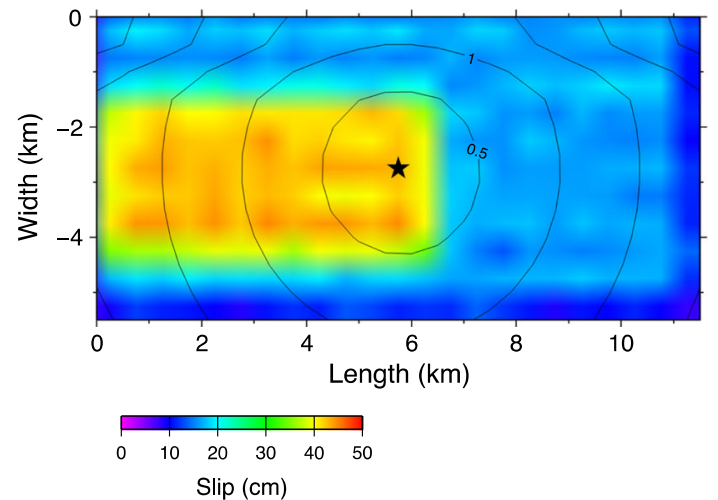

Figure 3

Slip model of the rupture scenario for the Zaqatala earthquake used in ground motion simulations 
3. Simulation of the Mw 5.9, 2012 Zaqatala Earthquake

We tested the 3D velocity model by simulating ground motion in the period range 3-20 s, recorded during the Mw 5.9, 2012 Zaqatala earthquake. The earthquake occurred on May 7, 2012 at 04:40:30 GMT in the Zaqatala region of Azerbaijan. The earthquake caused severe damage to thousands of residential houses in the epicentral area. It occurred on a thrust fault in the Greater Caucasus Range-Front fault system, and was followed by two large

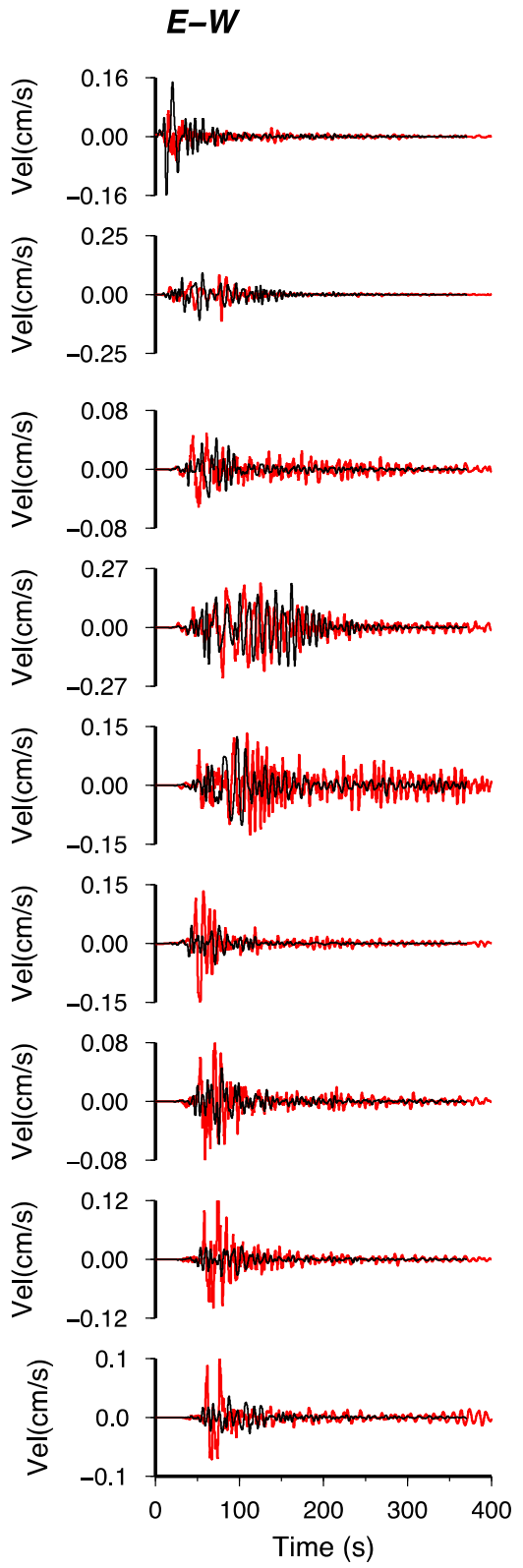

$N-S$
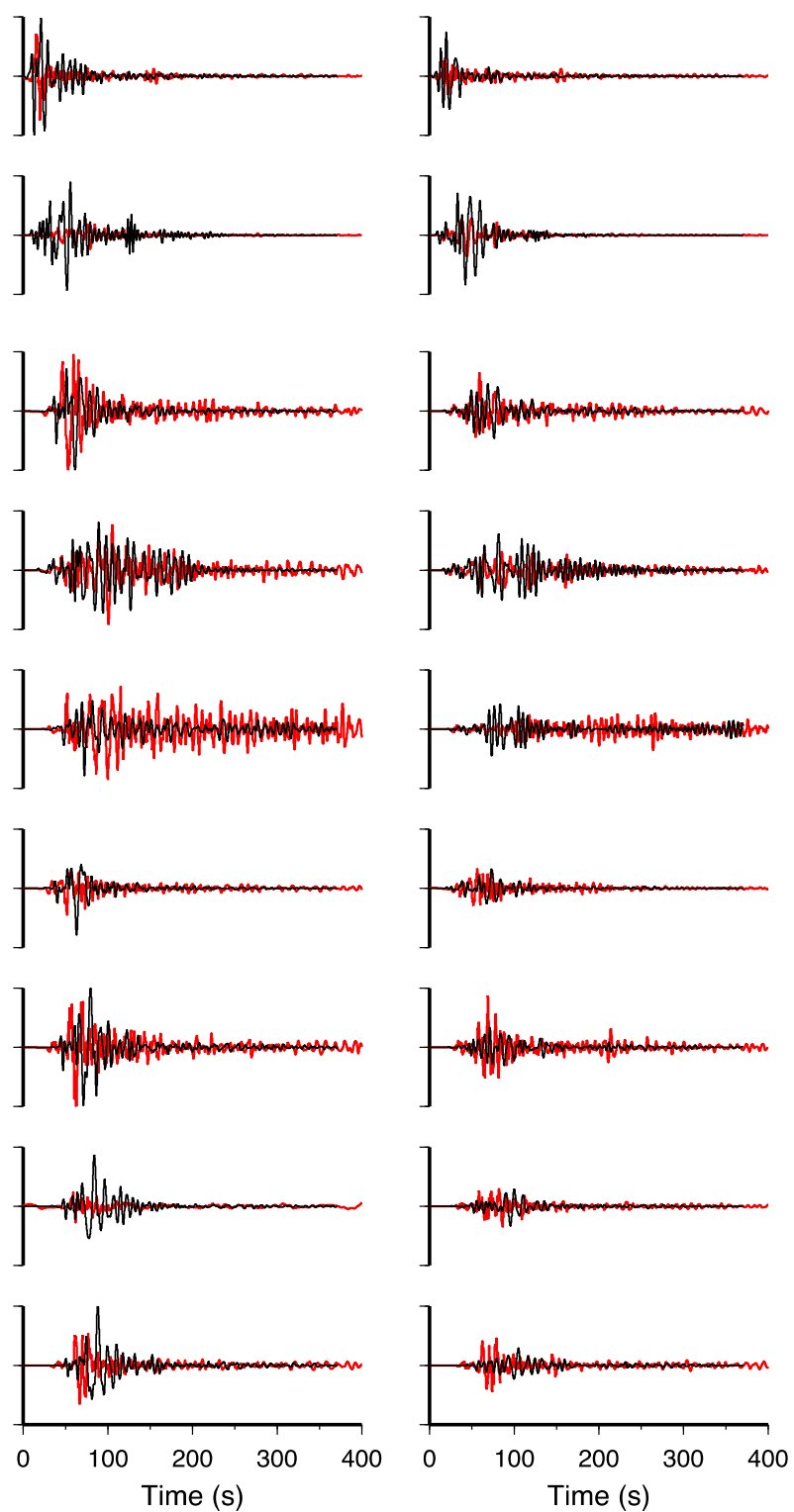

Figure 4

Time histories of simulated (black traces) and recorded (red traces) ground motion velocity for the Mw 5.92012 Zaqatala earthquake, bandpass filtered at $0.02-0.3 \mathrm{~Hz}$. The simulations were preformed using an extended fault rupture model. The stations name is indicated in each 
aftershocks of Mw 5.3 and Mw 4.8, respectively, that caused an additional damage. The earthquake was well recorded by 14 broadband seismic stations installed throughout the region and on various geological conditions. The particular location of the earthquake near the northern edge of the Kura basin and its thrust mechanism made it an ideal source for exciting the basin response and basin generated waves that travel across the region, therefore carrying information not only about the source but also about the subsurface structure. The recorded ground motion was simulated by a parallelized computer program based on a finite-difference method of the fourthorder accuracy in space (SW4) (Petersson and SjoGREEN 2012). SW4 is capable of modeling non-flat surface topography with good accuracy and unelastic wave propagation, as well.

In our simulations, we included the surface topography and used a kinematic model of earthquake rupture. The rupture propagates bilaterally on a $12 \mathrm{~km} \times 6 \mathrm{~km}$ planar fault. The strike and dip angles of the fault plane are $108^{\circ}$ and $82^{\circ}$, respectively, and the slip rake angle is $88^{\circ}$. The earthquake focal mechanism was obtained using moment tenser inversion of regional waveforms using Ichinose's technique (e.g., Ichinose et al. 2003). The slip distribution of the rupture scenario considered here is dominated by a single asperity in which the slip is $42 \mathrm{~cm}$ (Fig. 3). As it will be shown later, because of the relatively small size of the earthquake, the details of the slip distribution in the rupture model have insignificant effects on the computed long-period ground motion. The rupture velocity is computed as $80 \%$ of the local shear wave velocity. We used a Gaussian slip velocity function with a constant duration of $0.85 \mathrm{~s}$ estimated using the empirical rupture model of SOMERviLLE et al. (1999). The rupture initiation depth is $15 \mathrm{~km}$, and the seismic moment of the earthquake is $6.72 \mathrm{e}+17 \mathrm{Nm}$.

The finite-difference computation was performed using a minimum grid spacing of $300 \mathrm{~m}$ which ensures sufficiently accurate wave propagation modeling at frequencies up to $0.3 \mathrm{~Hz}$. The comparison between the simulated and recorded time histories of ground motion velocity, band-pass filtered at $0.05-0.3 \mathrm{~Hz}$ is shown in Fig. 4. A more quantitative assessment of goodness-of-fit is shown in Fig. 5. Due

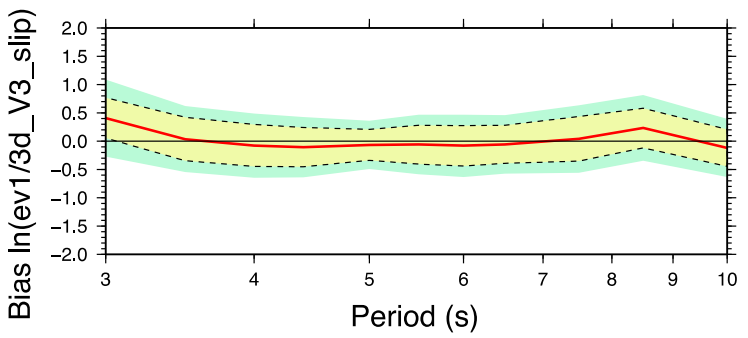

Figure 5

$5 \%$ damped spectral acceleration goodness-of-fit computed for the RotD50 horizontal component of ground motion from Zaqatala earthquake. Red line denotes simulation model bias averaged over 14 sites. Yellow shading denotes $90 \%$ confidence interval of the mean, and green shading denotes interval of one standard deviation

to its poor quality, the record at ZKT, the nearest station to the epicenter, was not used in the comparison. In general, the simulation reproduces the amplitude and duration of the recorded ground motion at several sites. The largest misfit is observed at stations SIZ and QUB for which the E-W component of ground motion is largely underestimated. Both sites are located near the basin edge where wave focusing caused by basin edge geometry (e.g., PITARKA et al. 1998) is expected to be more pronounced.

We quantified the overall comparison between recorded and simulated ground motion using goodness-of-fit measures for $5 \%$ damped horizontal spectral acceleration (Fig. 5). The ground motion acceleration time history at each station was obtained by computing the time derivative of the velocity time history. For an individual station, the residual $r\left(P_{i}\right)$ at each period $P_{i}$ is given by $r\left(P_{i}\right)=\ln \left[\operatorname{SAO}\left(P_{i}\right) /\right.$ $\left.\operatorname{SAS}\left(P_{i}\right)\right]$, where $\operatorname{SAO}\left(P_{i}\right)$ and $\operatorname{SAS}\left(P_{i}\right)$ are the observed and simulated spectral acceleration values, respectively. The model bias is obtained by averaging the residuals for all stations and the horizontal component RotD50 (Boore et al. 2006), at each period. A model bias of zero indicates the simulation, on average, matches the observed ground motion level. A negative model bias indicates over-prediction, and a positive model bias indicates the under-prediction of the observations. The simulated ground motion has no significant bias over the period range 3.5-10 s, indicating that the $3 \mathrm{D}$ model adequately captures the main characteristics of ground motion response at sites located in and outside the Kura basin. 
$E-W$
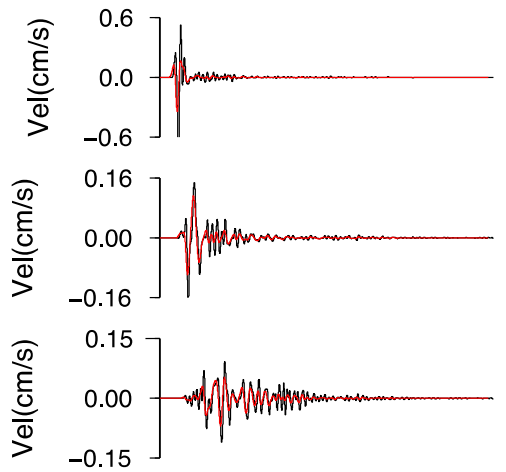

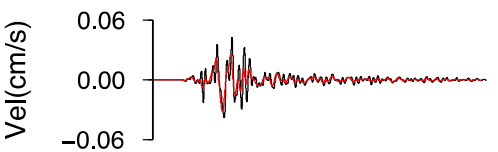
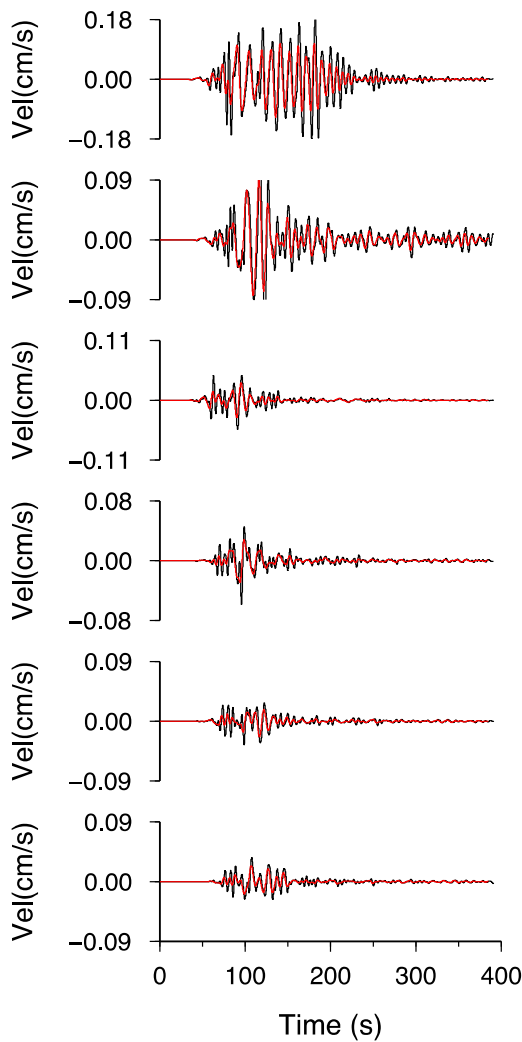

$N-S$
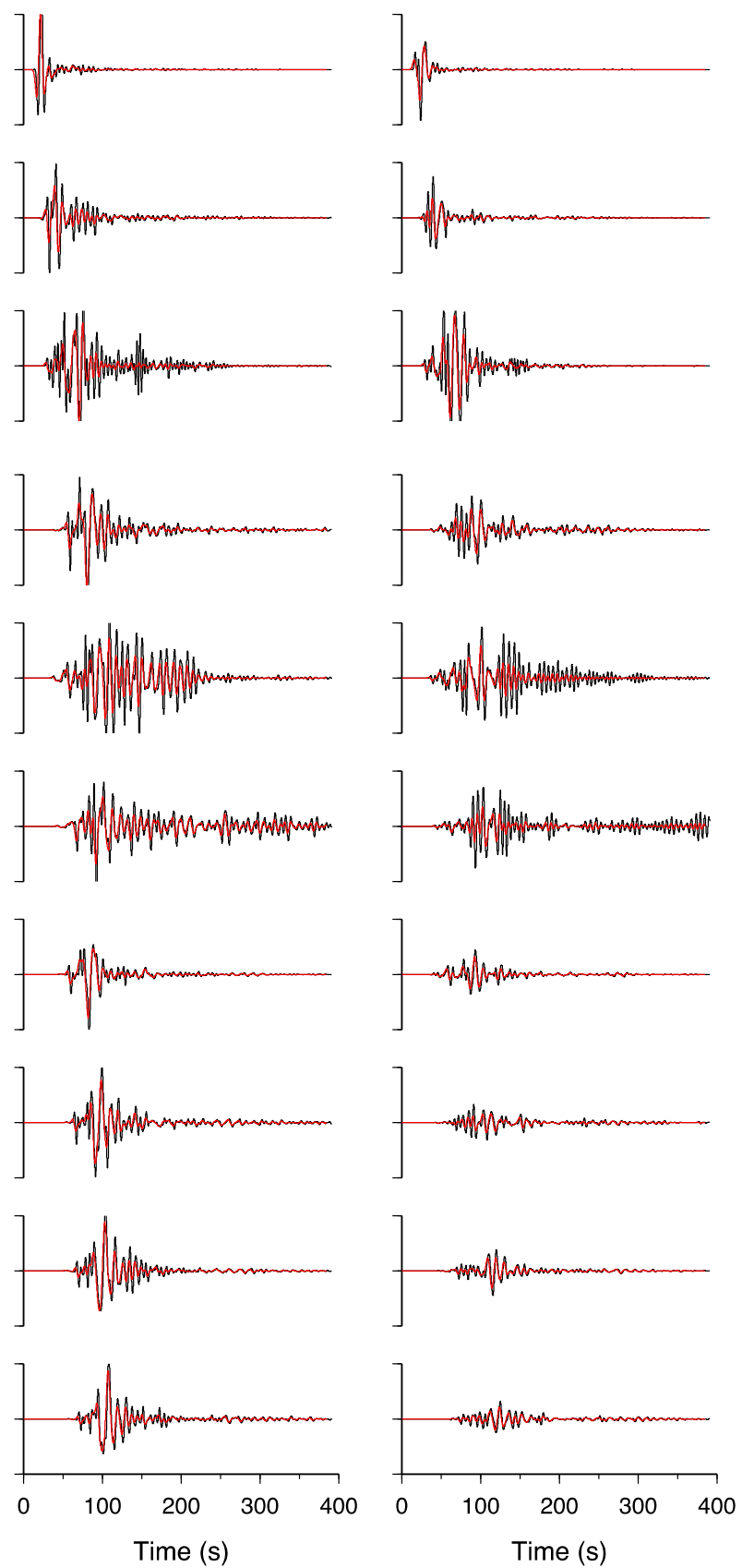

Figure 6

Time histories of simulated ground motion velocity for the Mw 5.92012 Zaqatala earthquake, using an extended fault rupture (black traces) and double-couple point source (red traces). Synthetics are band-pass filtered at $0.02-0.3 \mathrm{~Hz}$ 


\section{Ground Motion Sensitivity Analysis}

We performed several simulations of the Zaqatala earthquake to address the sensitivity of simulated ground motion to source and velocity models. We looked at the ground motion difference between a double-couple point source and kinematic fault rupture model. Because of the limited energy generated at long periods, it is expected that details of the rupture process of small and intermediate size earthquakes have a negligible effects on long-period ground motion (>3 s), especially at long distances (longer than several times the fault length). We tested this hypothesis by comparing simulated ground motion obtained with a kinematic slip model and doublecouple point source model of Zaqatala earthquake. We used the same seismic moment, mechanism, depth, and slip velocity function for both source models. The comparison of time histories of simulated ground motion velocity, band-pass filtered at $0.05-0.3 \mathrm{~Hz}$, is shown in Fig. 6. The two models produce ground motion with similar amplitudes, with the point source model producing slightly lower ground motion. The difference in ground motion amplitude remains almost the same at all stations suggesting that the discrepancy is not related to wave propagation effects but rather source effects. In the extended rupture model, the rupture propagates through a relatively large area, thus producing rupture directivity effects. The thrust mechanism generates upward directivity. Such effects can explain the observed difference between the point and extended source. The relatively small difference in ground motion between the two source models suggests that the point source model is valid for modeling intermediate size earthquakes $(M \sim 6)$ at long epicentral distances.
A common practice in seismic hazard assessment in areas with unknown 3D underground structure is the use of $1 \mathrm{D}$ velocity models in ground motion estimates. 1D velocity models, usually calibrated for travel time and surface wave amplitude, do not guaranty high-quality ground motion modeling in a broad frequency range. The main drawback of ground motion simulated with $1 \mathrm{D}$ velocity models is the enhanced band limited amplification of coda waves controlled by the resonant frequency of individual flat layers. In general, 1D models tend to produce larger than recorded long-period ground motion (PITARKA et al. 2014; DregER et al. 2015). Here, we compare ground motion simulated with the $3 \mathrm{D}$ model and the corresponding 1D local velocity model, as shown in Table 2. To avoid mixing source effects, associated with rupture propagating through a complex structure, and wave propagation effects, in both simulations, we used the double-couple point source model of the earthquake. Both models include surface topography. The comparison of simulated ground motion is shown in Fig. 7. It is evident that at basin sites, including BRD and KDR, the 1D model does a poor job at producing basin-induced waves which are correctly produced by the 3D model. In addition, at non-basin and distant sites, such as ATG, PQL, and SIZ, the wave trapping effect caused by the 1D model produces ground motion with unrealistic amplitude and duration. Maps of horizontal peak ground motion velocity, computed with the $1 \mathrm{D}$ and $3 \mathrm{D}$ velocity models, shown in Fig. 8, give a clear picture of the spatial extend of the effects of the 3D underground structure on ground motion amplitude. The contrast in terms of peak ground motion between the two models is strong in the Kura basin and along the Kaspian Sea coast.

Table 2

$1 D$ local velocity model

\begin{tabular}{lcccr}
\hline Layer thickness $(\mathrm{km})$ & $V_{\mathrm{P}}(\mathrm{m} / \mathrm{s})$ & $V_{\mathrm{S}}(\mathrm{m} / \mathrm{s})$ & Density $\left(\mathrm{g} / \mathrm{cm}^{3}\right)$ & $Q_{\mathrm{P}}$ \\
\hline 3.0 & 1700 & 800 & 2.1 & 300 \\
4.0 & 4000 & 2310 & 2.2 & 400 \\
6.0 & 5000 & 2886 & 2.5 & 500 \\
25.0 & 6500 & 3800 & 3.0 & 200 \\
& 7500 & 4350 & 3.2 & 250 \\
& & & 500 \\
\hline
\end{tabular}




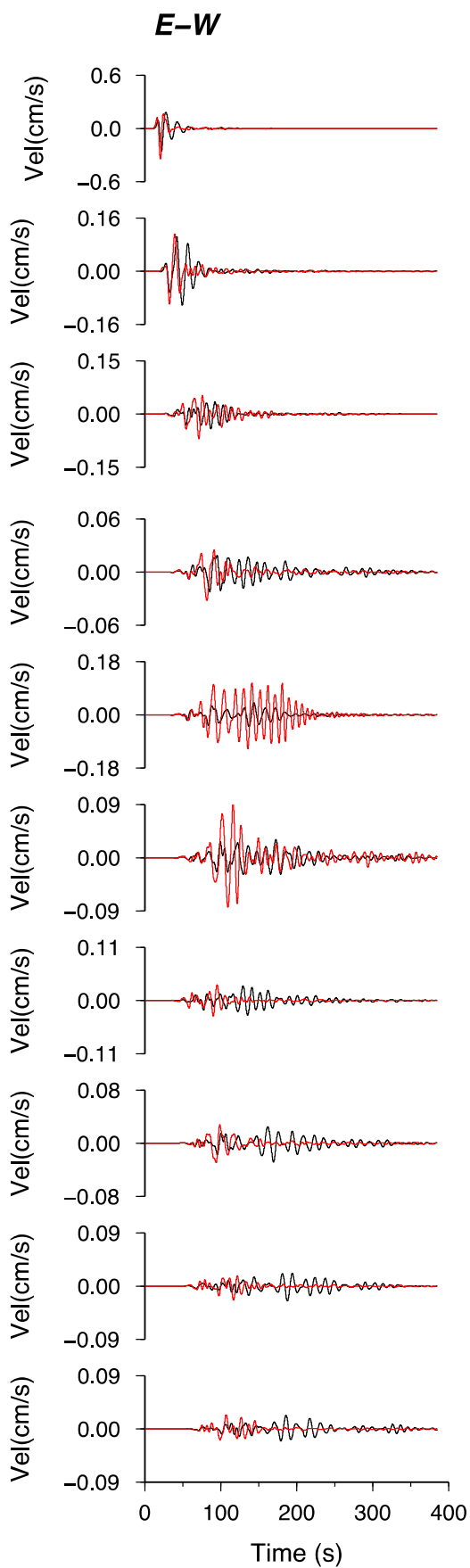

$N-S$
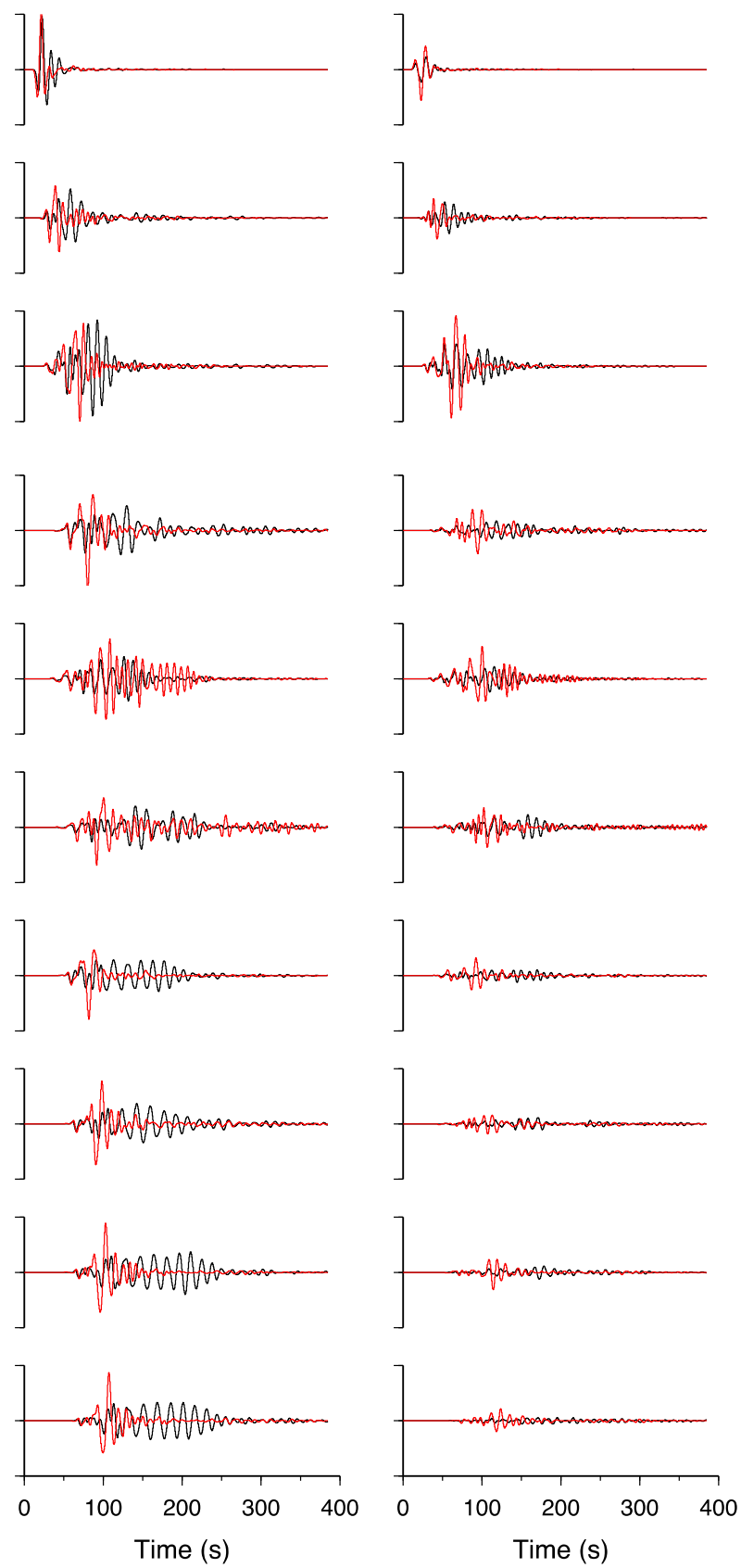

Figure 7

Time histories of simulated ground motion velocity for the Mw 5.9, 2012 Zaqatala earthquake, using the 1D velocity model (black traces) and 3D velocity model (red traces). Both simulations were preformed for a double-couple point source model. Synthetics are band-pass filtered at $0.02-0.3 \mathrm{~Hz}$ 

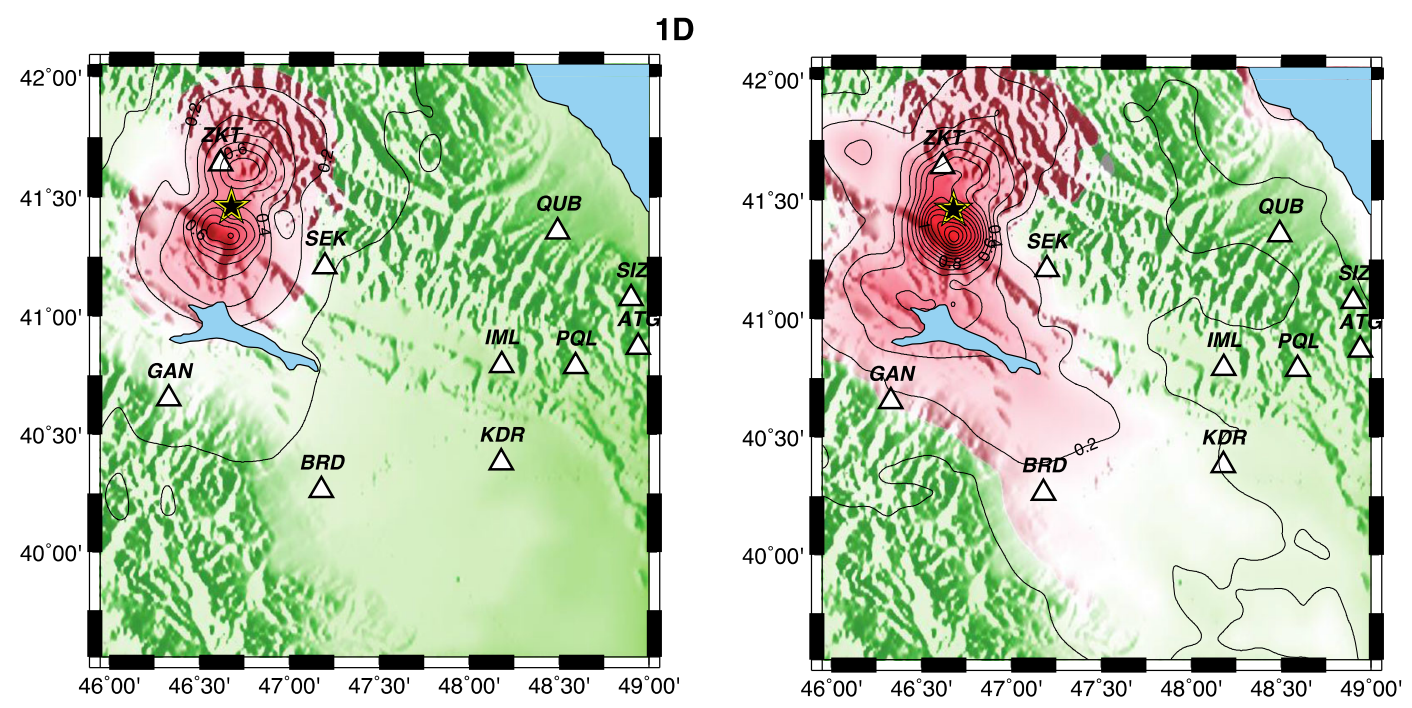

3D

Figure 8

Maps of long-period (3-20 s) horizontal peak ground motion velocity, simulated using 1D velocity model (left panel) and our 3D velocity model (right panel) and a double-couple point source model of the Mw 5.9, 2012 Zaqatala earthquake. Black star indicates the earthquake epicenter, and triangles indicate stations used in this study

We used selected snapshots of computed vertical component of ground motion velocity, shown in Fig. 9, to illustrate the contributions of the source and wave propagation effects on ground motion amplitude. First, due to the thrust focal mechanism, most of the source energy is directed toward northeast and southwest directions. Second, waves propagating in deep valleys along the Greater Caucasus mountain range and Kura basin are delayed and amplified due to lower velocity in the sedimentary layers. Third, and most importantly, the basin underground structure amplifies long-period surface waves and deflects their propagation direction from southwest to east. Significant wave reverberations are also seen along the Kaspian Sea coast. The fourth snapshot taken $264 \mathrm{~s}$ after the rupture initiation shows tremendous basin reverberations in the deepest part of the Kura basin. These basin-trapped waves greatly increase the amplitude and duration of coda waves.

\section{Conclusions}

In this study, we tested the performance of a preliminary 3D velocity model (GoK et al. 2011) in simulations of long-period ground motion in the Azerbaijan area and demonstrated the importance of considering 3D underground structure in estimating long-period ground motion response to distant earthquakes. The spatial distribution of the seismic stations used in developing the model limits its resolution, especially in areas with complex underground structure and in the central part of the Kura basin where the basin depth exceeds $6 \mathrm{~km}$. The $3 \mathrm{D}$ velocity model performed relatively well in simulations of ground motion from the Mw 5.9, 2012 Zaqatala earthquake recorded by the broadband Azerbaijan Seismic Survey network. Sensitivity analysis of ground motion to earthquake source models suggests that for intermediate size earthquakes $(M<6)$ in the Greater Caucasus Range-Front fault system, long-period ( $>3 \mathrm{~s}$ ) ground motion computed in the Kura basin is not sensitive to fault rupture details. Therefore, simple double-couple point source modeling of small and moderate size earthquakes in the region can produce reliable results. The comparison between computed and recorded ground motion in the frequency range of $0.05-0.3 \mathrm{~Hz}$ suggests that the 3D model used here lacks resolution and need improvements in the central part of the Kura 

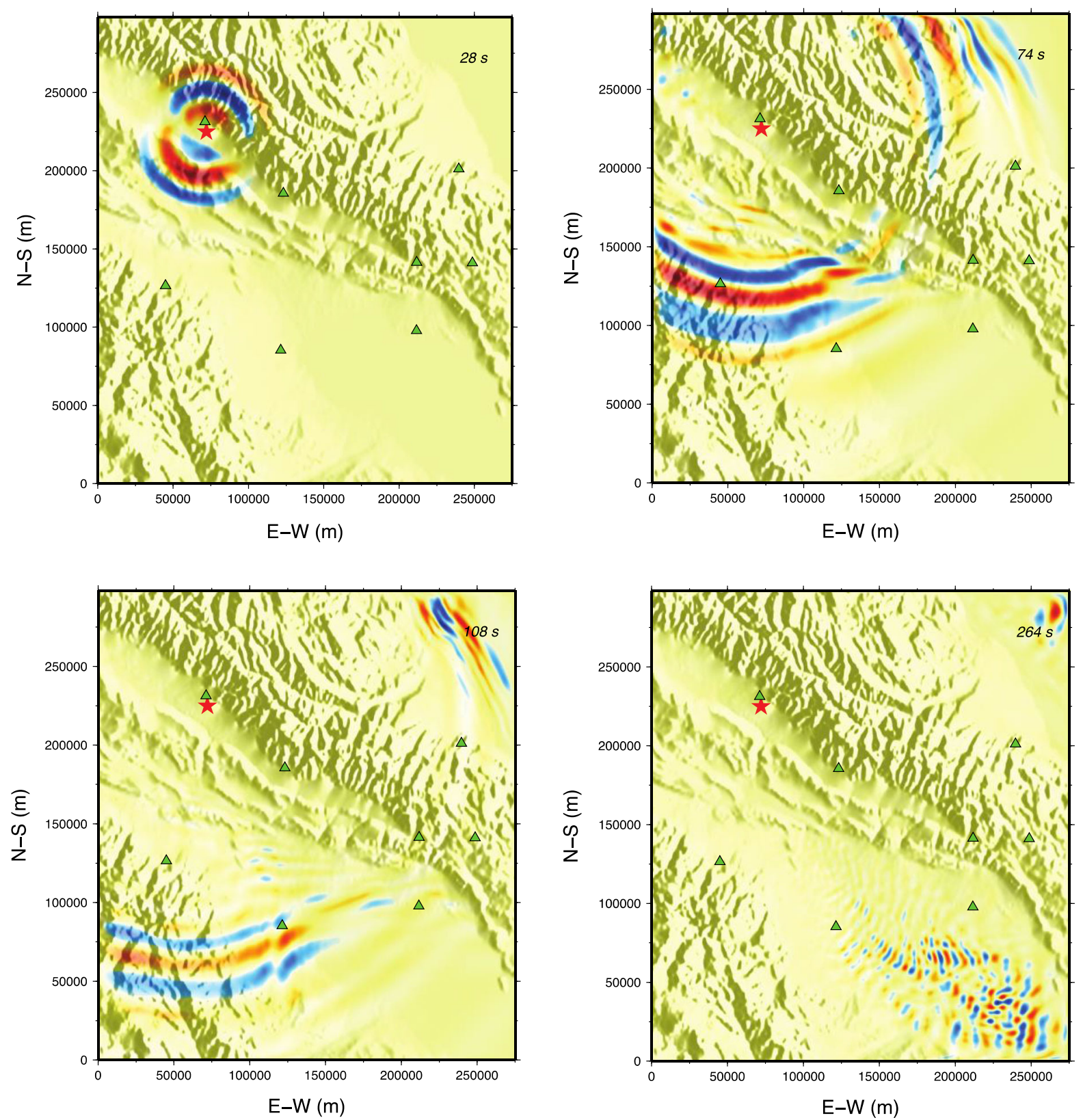

Figure 9

Snapshots of the vertical component of simulated ground motion velocity at four different times. The snapshot's time is indicated on each panel. Red star indicates the simulated earthquake epicenter, and green triangles indicate stations used in this study

basin, and in particular in the Kaspian Sea coast where the simulation of the Zaqatala earthquake largely underpredicts the effect of basin edge on ground motion velocity.
Open Access This article is distributed under the terms of the Creative Commons Attribution 4.0 International License (http://creativecommons.org/licenses/by/4.0/), which permits unrestricted use, distribution, and reproduction in any medium, 
provided you give appropriate credit to the original author(s) and the source, provide a link to the Creative Commons license, and indicate if changes were made.

\section{REFERENCES}

Boore, D. M., Watson-Lamprey, J., and Abrahamson, N. A., 2006. Orientation-independent measures of ground motion, Bull. Seism. Soc. Am. 96, 1502-1511.

Dreger, S.D., Beroza, G.C., S.M. Day, C.A. Goulet, T.H. Jordan, P.A. Spudich, and J.P. Stewart (2015). Validation of the SCEC Broadband Platform V14.3 Simulation Methods Using Pseudospectral Acceleration Data, Seism. Res. Lett., 86, 1, 39-47.

Forte AM, E Cowgill, T Bernardin, O Kreylos and B Hamann (2010) Late Cenozoic deformation of the Kura fold-thrust belt, southern Greater Caucasus. Geological Society of America Bulletin, 2010), 122(3-4):46. doi:10.1130/B26464.1.

Graves, R. A. Pitarka (2010). Broadband ground motion simulation using hybrid approach, Bulletin of Seismological Society of America. Bull. Seism. Soc. Am., 100, 5A, 2095-2123.

Gök, R., R. J. Mellors, E. Sandvol, M. Pasyanos, T. Hauk, R. Takedatsu, G. Yetirmishli, U. Teoman, N. Turkelli, T. GodOLADZE, and Z. JAVAKISHVIRLI (2011). Lithospheric velocity structure of the Anatolian plateau-Caucasus-Caspian regions: Journal of Geophysical Research, v. 116, p. B05303, doi:10. 1029/2009JB000837.

Ichinose, G. A., J. G. Anderson, K. D. Smith, and Y. Zeng (2003). Source parameters of eastern California and western Nevada earthquakes from regional moment tensor inversion. Bull. Seism. Soc. Am., 93, 61-84.

Jackson, J., Priestly, K., Allen, M.B., and Berberian, M., 2002, Active tectonics of the South Caspian Basin: Geophysical Journal International, v. 148, p. 214-245, doi:10.1046/j.1365-246X. 2002.01588.x.

Kadirov, F (2000). Filtering of Gravity Data Using the Hartley Transform: A Case Study of the Kura Intermontane Trough. Izvestiya, Physics of the Solid Earth ISSN Vol. 36, No. 10, 866-872.

Kondorskaya N.V. and N.V. Shebalin, (1977), eds., New Catalog of Strong Earthquakes in the U.S.S.R. from Ancient Times through 1977, NOAA National Geophysical Data Center Report SE-31, Boulder, Colorado, 1982. (Update and English translation of Noviy Katalog Sil'nykh Zemlyetryaseniy na Territoriy SSSR Drevneyshikh Vremyen do 1975, USSR Academy of Sciences, Moscow, 1977).

Petersson, N. A., and B. Suögreen (2012). Stable and efficient modeling of anelastic attenuation in seismic wave propagation, Comm. Comput. Phys. 12, 193-225, doi:10.4208/cicp.201010. 090611a.

Pitarka A., P. Somerville, Y. Fukushima, T. Uetake, and K. IriKURA. (2000). Simulation of near-fault strong ground motion using hybrid Green's functions, Bull. Seism. Soc. Am., 90, 566-586.

Pitarka, A., K. Irikura, T. Iwata and H. Sekiguchi (1998). Threedimensional simulation of the near-fault ground motion for the 1995 Hyogo-ken Nanbu (Kobe), Japan, earthquake. Bull. Seism. Soc. Am., 88, 428-440.

Pitarka, A., A. Al-Amri, M. Pasyanos, A. Rodgers, and R. MelLORS (2014). Long-Period Ground Motion in the Arabian Gulf from Earthquakes in the Zagros Mountains Thrust Belt. Pure Appl. Geophys. doi:10.1007/s00024-014-0858-z.

Pulido, N., Z. Aguilar, H. Tavera, M. Chlieh, D. Calderon, T. Sekiguchi, S. NAKai, and F. Yamamzaki (2015). Scenario source models and strong ground motion for future mega-earthquakes: application to Lima, central Peru. Bull. Seism. Soc. Am., 105, 368-386.

Rodgers, A., W. Walter, R. Mellors, A. M. S. Al-Amri and Y. S. ZHANG (1999). Lithospheric structure of the Arabian Shield and Platform from complete regional waveform modeling and surface wave group velocities, Geophys. J. Int., 138, 871-878.

Somerville, P. G., K. Irikura, R. Graves, S. Sawada, D. Wald, N. Abrahamson, Y. Iwasaki, T. Kagawa, N. Smith, and A. Kowada (1999). Characterizing crsutal earthquake slip models for the prediction of strong ground motion, Seism Res Lett, 70, 59-80.

Storchak, D.A., D. Di Giacomo, I. Bondár, E. R. Engdahl, J. Harris, W.H.K. Lee, A. Villaseñor and P. Bormann, (2013). Public Release of the ISC-GEM Global Instrumental Earthquake Catalogue (1900-2009). Seism. Res. Lett., 84, 5, 810-815, doi: $10.1785 / 0220130034$.

(Received November 13, 2015, revised April 27, 2016, accepted April 30, 2016, Published online May 13, 2016) 